\title{
Refusal as a democratic catalyst for mathematics education development
}

\begin{abstract}
Authors:
Dalene Swanson ${ }^{1,2}$

Peter Appelbaum ${ }^{3}$

Affiliations:

${ }^{1}$ Educational Research

and Engagement, Nelson

Mandela Metropolitan

University, South Africa

${ }^{2}$ Faculty of Education,

University of Alberta, Canada

${ }^{3}$ Department of Curriculum, Cultures, and Child/Youth Studies, Arcadia University, United States

\section{Correspondence to:}

Dalene Swanson

Email:

dalene.swanson@nmmu.ac.za

Postal address:

PO Box 32180

Summerstrand, Port

Elizabeth 6019, South Africa

\section{Dates:}

Received: 21 Aug. 2012

Accepted: 21 Oct. 2012

Published: 04 Dec. 2012

How to cite this article: Swanson, D., \& Appelbaum, P. (2012). Refusal as a democratic catalyst for mathematics education development. Pythagoras, 33(2), Art. \#189, 6 pages. http://dx.doi.org/10.4102/ pythagoras.v33i2.189
\end{abstract}

(C) 2012. The Authors. Licensee: AOSIS OpenJournals. This work is licensed under the Creative Commons Attribution License.
Discussions about the connections between mathematics and democracy amongst the general populace have not been explicitly well rehearsed. A critical relationship with democracy for mathematics education may involve directing and redirecting its purposes. But, we ask, what if the 'choice' to not participate in experiences of mathematics education, or in its (re)direction, were itself also a critical relationship with mathematics education? What if this refusal and disobedience to the evocative power of mathematics were a democratic action? We argue that consideration of mathematics education for democracy and development must take seriously specific acts of refusal that directly confront the construction of inequality common in most development contexts. Globalisation and development discourses, via citizenship and nationalism, construct relationships with learners and mathematics education in very specific ways that delimit possibilities for egalitarianism and democratic action. But, might such action not be recognised, not as refusal to participate per se, but as a refusal to participate in mathematics education's colonising and/or globalising neo-liberal gaze? In arguing for the opening of a position of radical equality, we introduce Jacques Rancière to mathematics education theory, noting that for Rancière emancipation is the intentional disregard for ideological narratives such as the ones produced by mathematics education discourses. Thus, we provoke serious reconsideration of the assumptions behind most school improvement and professional development projects, as well as mathematics education policies and practices framed by globalising development discourses, and in the process we challenge our colleagues to consider 'refusal' not as deficit or failure, but as a critical position of radical equality in relation to mathematics education.

\section{On mathematics and democracy}

Discussions about the connections between mathematics and democracy amongst the general populace have not been explicitly well rehearsed, other than to either assume that mathematics has nothing to do with anything political, being neutral in form and practice, so it has nothing to do with democracy, which is something political; or that it is implicitly democratic. This latter assumption is underpinned by a conflation of capitalism with principles of democracy, so that if mathematics has economic utilitarianism, usually via technology and development, then it is per se democratic in nature. Skovsmose and Valero (2001, p. 39) reference this last position as an assumption of mathematics education's 'intrinsic resonance' with democracy. In contrast, arguments for its 'intrinsic dissonance' have been relayed by mathematics educators conscious of the role mathematics plays in the social domain as a discourse of power, and of its deleterious effects on the lives of many people. This dissonance has been manifest either through lack of access to the discourse and practice of mathematics in the light of its gatekeeping role to avenues of employment, further education and social 'advancement' within the hierarchies of discourses in the social domain, or because of their alienation from it and the strong negative emotions it often arouses. Skovsmose and Valero (2001) note in this regard:

mathematics has a power that escapes the boundaries of rationality and argumentation, and through its applications, it has become one of the forces of social reflexive modernization. ... As a subtle and implicit force, disguised and protected by the ideology of certainty, ... the destructive power of mathematics has escaped the suspicions of citizens, scientists, and social scientists. (p. 41)

Skovsmose and Valero (2001) also reference a third position: mathematics education's 'critical relationship' with democracy, in the sense that it can go both ways. In this sense, they state that:

a mathematics education that is committed to democracy cannot simply rest on the intrinsic qualities of mathematics or the conceptual constructs of the discipline itself. Instead, many social, political, economic, and cultural factors have to be seen as constantly directing and redirecting its development. (p. 43)

We ask: What if the 'choice' to not participate in experiences of mathematics education, or in its direction or redirection, was in itself also a critical relationship with mathematics and mathematics education? What if this refusal and disobedience to the evocative power of mathematics were a democratic action? 
The scene is set through a 'critical rhizomatic narrative' rendering of deliberations and dialogues on the 'construction of disadvantage' through the discourse and practice of school mathematics in a post-apartheid South Africa (Swanson, 2005). In her research journey, explicated through narrative methodology, Dalene encounters Moses, a South African teacher and (post)graduate student, at an international education conference.

During the conversation, Moses asks about Dalene's research and what her research intention is (Swanson, 2005, 2007b). After listening to her explanation for a whilst, and hearing her use the word 'empowerment' on several occasions, he responds politely, but directly (in a recognisably cultural 'South African' manner) with:

Empowerment ... empowerment ... empowerment! They tell us we have a lack, that we are supposed to be here', [he gesticulates a movement suggesting 'progress'], and that we need to be here, and then here. They tell us that we are disempowered and inform us what must be relevant for us to be empowered. I don't feel disempowered, but I am told that I am disempowered and what I have to be to be empowered. (2005, pp. 217-218, 2007b, pp. 17-18)

We (Peter and Dalene) are revisiting those aspects of our past research that have been gathering momentum as we each pursue questions of mathematics and democracy. For Dalene, the full weight of Moses' response and the power of its implications for positions of activism at the time, including for her own activism associated with mathematics education and democracy, felt tremendous. As much as Moses' statement was profoundly provocative, it concomitantly provided a powerful self-learning opportunity and opened up a critical, revelational space for self-interrogation. Mathematics education research was propelled by this conversation between researcher and teacher into questions about the epistemic locations of our activism and the ontology of knowing not only what 'truth' is, but what might be accepted, at least for the moment, as fundamentally 'right' and 'just'. Dalene asked herself, 'Who authors this?' raising for us now, as we look back on such research moments, how critical to democratic action authorship might be. How interwoven with authorship and the feelings of authorship are the principles of power and the referents for defining or judging the ethics of action? (Swanson, 2007b).

Peter thinks back to Gus, a strong and interested student who slowly opted out of a path to 'success' once his grades on assignments had assured him of a passing grade in mathematics (Appelbaum, 2008). The choice to slip out of engagement enabled Gus to spend more time on his painting and more time with his girlfriend:

When Gus first stopped coming to class every day, I asked him if anything was wrong. He told me absolutely not. He really enjoyed our class, but he had other things to do right now. ... I was bewildered. Here was possibly the strongest student in the class, someone who so easily caught on to every idea in our course, and he was simply opting out. I pushed him on this, and he told me it had nothing to do with me, and he hoped to take the next semester of mathematics with me as his instructor, but his grades in the first part of the semester were good enough to let him coast right now and not end up with lower than a ' $C$ ' in the course, which would be good enough. But Gus should be a mathematics major, I thought! This class should be the first priority for him, because he is so good at it. Gus, though, was happy as an art major, and his painting was his first priority.

Both Moses and Gus represent a potentially vital aspect of the democracy we wish to bring to the mathematics education conversation: refusal. Sometimes 'refusal' takes the form of rejecting labels or categories assigned by others. In other contexts, it is enacted as a rejection of values and beliefs. At still other times it might be termed 'disobedience'. Much of mathematics education has been demonstrated to serve a disciplining or formatting and pacifying function in which students implicitly learn to do what is expected of them (Skovsmose, 2012): to solve assigned problems, to memorise standard algorithms, to complete tasks. Yet democracy has at its core the idea of the rights of the individual to pursue their own destiny and forms of happiness, an idea that might entail disagreeing with a dominant social paradigm or the will of an authority (such as a teacher or a government set of learning objectives).

And so we ask, what is Moses' location, and what are the set of stimuli producing this articulation of his position on 'empowerment'? Who is 'telling' Moses that he is disempowered? What is the source of these messages? Why is he personalising this perspective on disempowerment? Is it so coercively embedded in the fibre of social context and the dominant discourses in the social domain that, even as he contests it, it carries the authorial voice of the 'deficit' meta-narrative in such a way that it holds the production of meaning ransom, even as it precedes any verbal articulation of it? (Swanson, 2005, 2007b). We ask, too, why Gus so easily dismisses the potential of mathematics, given the ease with which he excels and the apparent enthusiasm with which he displays creative experimentation in class with others. In what ways is painting and spending time with one's girlfriend more obviously satisfying in the immediate sense than school mathematics, and, in this way, how might we condemn mathematics for not living up to its promise in this situation?

When Dalene first had her conversation with Moses, she was humbled by his contestation of the extraneous gaze (semiotically recruited through her articulation of 'empowerment'), which produced and reified positions of disempowerment for him and 'his people' in ways that categorised, objectified, essentialised and homogenised communities, oppressively holding them to these descriptions through the language of disempowerment (Swanson, 2005, 2007b). When Peter first experienced the bewildering dismissal of mathematics by Gus who had so relished the opportunity to ask new questions and invent new mathematical investigations, he, too, was humbled by the contestations of the extraneous gaze (semiotically recruited through his articulation of 'engagement'), which produced and reified positions of disempowerment for Gus and 'students like Gus' who 'can't appreciate the potential of mathematics' for their pursuit of happiness and pleasure. 
In contrast to both Moses and Gus, the youths who worked with Brazilian artist Vik Muniz on an exhibit inspired by the sculptures of Giacometti knew that the kind of people who commonly visit museums are those who have the power to show them what they can never have. Their exhibit turned the tables for once, as the artists (the children) became the ones producing desire: the original sculptures were of people holding various things up with their hands. The youths' sculptures of themselves holding invisible items, combined with the placement of those items in a black bag, deprived visitors of the knowledge of what each child was holding (Magill, 2000). The contrast is one not of sculpture versus mathematics, but of the location of the refusal. The children in Salvador, Brazil, located their refusal as a characteristic of the relationship between themselves as creators of knowledge and their audience as people desiring to know.

Was Moses perhaps working to distance himself from the community in which he taught, so that he was not painted with the same brush of 'poverty'? At face value, he certainly did not fit the mould of 'impoverishment' or 'disadvantage' in the stereotypical sense (except through the construction of 'race', whose historical imperatives have tied it to the latter constructions, especially within the apartheid context). Hewas a teacher, studying for his master's degree. Yet, as if to belie these distinctions, he made remarks in general conversation to the effect that he was 'just a Soweto boy'! Why did he feel he needed to do this, Dalene questions in her mind, and how did it relate, via the processes of positioning and posturing, to his remarks on disempowerment? Was he speaking from a position of privilege or disadvantage? (Swanson, 2005, 2007b). What was Peter hoping that mathematics could 'give' Gus that painting or social interactions would not? How is mathematics typically implicated in fantasies of empowerment, and how are these fantasies tied up with our cultural stereotypes of mathematically based work-lives and status? In what ways might we read Gus's choices as a seizure of self-determination via the disempowering act of refusing mathematics? How might we characterise the attitudes and present experiences of the youths who worked with Vik Muniz, and what these types of experiences of manipulating desire and challenging expectations of knowledge might promise in contrast to the expectations that teachers of mathematics hold for students of mathematics?

Were Moses and Gus resisting being positioned as 'disempowered', or are these legitimate 'disempowered voices' speaking back to the referential gaze that produces constructed 'disempowerment'? (Notice how our language eludes us ... constructing even as we attempt to deconstruct it.) In the interests of a critical analysis that addresses power as a characteristic of social relationships, and that makes available the referential gaze that produces the relativities of power relationships that produce it, is it then permissible to ask if Moses or Gus might be 'entitled' to make their calls as insiders? Or should we interpret their refusals as having more to do with resistance to a perceived subject position ... a desire to be an outsider to 'disempowerment' rather than a socially enforced insider through the localising discourse on mathematics?

\section{On development}

Conceptualisations of 'the learner' are most often driven by dominant Western educational discourses that normalise competition and draw on individualistic ideological investments globally. These prevailing discourses enable life opportunities for individuals within certain valued groups whilst delimiting opportunities for others. In so doing, they reify dominant cultural formations over localised ones, and these dominant discourses become the master print for entry or denial of access. Life opportunities are, however, beyond a question of mere 'access.' Normalised assumptions inhabit questions of what is valued, what is conserved and what is foreclosed in terms of being and imagining within other frames of reference. The ways in which these ideological assumptions impact on the recognition and validation of indigenous, generational or localised ways of knowing and being, and how they permit or enclose imaginative possibilities for communities to be otherwise, are all interconnected and relate directly to the false promise of the ends of freedom and egalitarianism, and misconception of well-being through the instrumental and material means of techno-scientific and economic 'progress' (Swanson, 2010). Increasing neo-liberalisation of institutions and the global modernisation agenda has set the terms of global economic and social participation, by increasing the monitoring and regulation of individuals, groups and targeted communities. Such measures serve to perpetuate the global neo-colonial project. The current conception of development, framed as it is as 'economic progress' within the neo-colonial project, has become a Truth that tolerates little resistance, that excludes a range of other possible meanings and ways of engagement, and that attempts to silence alternative voices. The more discourses on development become increasingly foreclosed in these terms, the greater freedom and the possibilities of freedom and egalitarianism, as framed by globalising development discourses, become enclosed (Swanson, 2010, 2012).

The issue of position and empowerment percolates in mathematics education discourse particularly when one considers the role of mathematics education in programs of 'development', and the role of 'development' programs in supporting the mathematics education of learners in countries and communities targeted by development agencies or with governance framed by development discourses. Development as a concept presumes a need for development on the part of the targeted communities. In this sense, any development program situates the communities that are ostensibly aided as 'lacking' and in need of assistance. At the same time, political discourses within developing countries often frame the needs of their citizens in terms of deficit and economic lack. Many observers of such communities, including some members of the communities themselves, would agree with such characterisations. Yet the assumption is that the community members need the 
wisdom of the experts in the agency (or their development government) as well as the financial and material support. A radical assumption of equality would work against such assumptions, suggesting that mathematics education with and for development would begin with a refusal of help in favour of a program of collaboration. We begin with the acknowledgement that people are simply 'where they are' because they are, in this cultural, political, historical, etc. moment, where and how they are, with others who are also 'where they are'. People are by their very nature incapable of being elsewhere. As Rancière (2009) notes, people are not 'unable' because they ignore the reason for being there; they are 'unable' because 'being unable' means the same thing as being there or here. Those branded 'in need of mathematics' for themselves, for development, or for any reason, are tautologically defined as needing mathematics simply because of whom and where they are. Development in this sense is little more than a mechanism of defining inequality.

Development with rather than for or in spite of begins with the radical assumption of equality and the presumption that all participants contribute important components of a successful mathematics education project. A first principle of such a mathematics of and with development would understand that the development project cannot declare in advance what the outcomes will be for others that will benefit, but instead must begin prior to such setting of objectives, in the coming together of participants to discuss the range of possibilities. In order to break the cycle of expertise from outside, the initial meetings need to create spontaneous activities that work to avoid the presumption that some collaborators need to be led by the others in defining purpose, methods of working and forms of knowledge. Likewise, development governments who speak on behalf of their citizens, thereby structuring a patriarchal relationship with them, reproduce the inequality of that relationship. Such governments who claim to know, on behalf of their citizens, what is 'good' for them, reinforce and reproduce the deficit positions. This performs the inequality as natural. This is a subtle shift from well-known theorisations of 'critical mathematics education' that attribute a 'critical competence' to learners (Skovsmose, 2009), in which it might still be imagined that this competence is 'given' by authorities, to the more provocative stance of a priori equality.

Rancière (2009) does not directly address the function of mathematics per se in his essay on the method of equality. We propose, however, that mathematics could be included in what he refers to as art or literature: mathematics is one form of activity in which descriptions become narratives larger than themselves, reasons for inequalities. In fact, Dowling (1998) speaks of the recontextualising gaze of mathematics, drawing on the work of Bernstein here, where this gaze is cast across other social events and practices and is recontextualised, through its dominance, to the terms of mathematics. Here mathematics becomes the judge of those events and practices, colonising them in the process. Others have suggested the fabricating power of mathematics, in which 'facts' and 'realities' are the result of mathematical action (Lawler, 2010; Skovsmose, 2012). Emancipation, for Rancière, is an intentional disregard for ideological narratives, rather than, as frequently taken in these sorts of discussions, a lack of awareness of the functioning of narratives in establishing common sense. In the same way that we might understand art or literature as triggering passions by which new forms of balance or imbalance uproot icons of faith, emblems of power, or poetic hierarchies, mathematics might in a new form of development project perform this radical manoeuvre of equality, refusing the distinction between those who know and those who do not, those who have and those who do not. Indeed, democracy might well be defined as the exercise of power by the unqualified or unauthorised, the un-entitled. Mathematical 'knowledge' in this exercise of power matters less than the claim to mastery presumed in any claim to knowledge.

\section{On globalisation}

Development is advanced through discourses of globalisation and the imprinting of universally 'good' goals or 'best practices' onto local, particularised settings. 'Globalisation' refers to the way in which capitalism has spread across the world, changing the trade agenda, displacing indigenous companies and communities in favour of multinational corporations (Myers, 2003). The effects of globalisation are not just commercial, since what is at stake are the national cultures and political bodies underpinning and supported by resident industries. The more capitalism spreads, the more it works to dissolve the efficacy of national domains, dissipating local traditions and values in favour of 'universal' ones. The only way to offset the increased homogeneity and to assert the worth of the particular against the global is to cling with ever greater tenacity to one's specific ethnic or indigenous fantasies (Myers, 2003, p. 106). Here, too, we find that local and global must be identified and integrated within each other, as 'glocalisation' in an effective creolisation of culture (Appelbaum, 1995), if there is to be an enactment of radical equality.

Development seems to presume that mathematics will have a salutary effect on a community and in the process on democratic life. Mathematics education as a component of development projects would be charged with transforming the taste of a people, taking the community by surprise, and promoting the 'higher' mathematised culture over the 'lower', 'uneducated', rural (ignorant) masses. Partly, the need for development is generated by a culture of fear propagated in the South African context by discourses of educational crisis. Media and government agency communications raise alarm about the dire circumstances of South African students' poor performance in mathematics. South Africa's participation in the TIMMS-R study, in which South Africa ranked 48 out of 48 nations competing, was used to beat the drum of despair and galvanise South Africans into panic mode over fears for the economy, drawing attention away from issues of corruption, fraud and poor governance. Almost every major multinational or other major corporation in South Africa 'benevolently' gives money to schools and universities to 
bolster their mathematics and science in the 'hopes' of an 'improvement' for the 'economy's sake' (which makes their social responsibility portfolios look impressive). The more the stakeholders of the education industry in South Africa perform 'crisis' over the 'dismal mathematics results in South African schools', the narrower, more prescriptive, more functionalist and instrumental the curricula, methods and discourses around mathematics education and achievement become. The crisis serves the interests of the managerialist mindset of the newly neo-liberal post-apartheid South Africa and, more significantly, the urgent need for revolutionary educational programmes.

As Rancière (2012) describes these revolutionary educational programmes, they tend to fit one of two paradigms: the education of the public by artistic impregnation, as in a theatreof-the-people, by the people, for the people; or as a poetic celebration of the local spirit, in which the light shining down from the outside onto the locality merges with the sap rising from the ground up. Attempts to meld the two paradigms end up sounding like Jules Michelet in the 19th century: 'Feed the people from the people' (Rancière, 2012, p. 13). But this relationship of people to people, in which the development worker-educator takes the place of the travelling salesman, turning mathematics and forms of mathematics education into commodities that people will buy into (a focus of desire), ends up having nothing in common with the local passions if it is constructed to begin with as something to be desired. Rancière notes how seductive it is to imagine a theatre of the people that operates like a 'mirror in which the people observe their own actions' through a 'performance without separation, in which the engaged citizen writes and enacts his own victories' (cited in Hallward, 2009, p. 146). In this way, we can see the pull to engage with mathematics education as a theatre of the people, in which increasingly mathematically literate citizens employ mathematics and its forms of question and response as a tool of reflection on democracy and empowerment. However, as Hallward (2009, p. 157) writes, 'Rancière knows as well as anyone that the theatre is never more theatrical than when it finds new ways of blurring, without eliminating, the boundaries with the nontheatrical.' And so it would go with mathematics education as a theatre of the people: one would need to abandon those features of the theatrical that run counter to the radical equality at the heart of such democratic action (for example, those forms of mathematics as a theatre of democracy in which the incorporation of those who have no part is controlled in some way by the supervision of 'appropriately managed' institutions) if one were to have any hope for such a theatre to enable democratic interaction. Examples of such practices to be abandoned include the scripting of lessons and the assignment of particular objectives from outside, the creation of purposes for the project, or the crafting of plans that leave no room for local improvisation or adaptation.

\section{On citizenship}

Common progressive and utilitarian rhetoric on the 'importance' of mathematics learning in schools often advocates 'good citizenship' and vocational advancement.
Echoing the languages of Michelet after the French revolution, a 'successful citizen' would be someone with access to the power of mathematics to 'know the world'. This is because of the description of the nature of mathematics as 'one way of trying to understand, interpret, and describe our world' (Ministry of Education, Province of British Columbia, 2007, p. 13). Yet the politics of such 'coming to know' is most commonly denied, so that the ability of Mathematics to enable its knowing subjects to 'describe our world' is purportedly divorced from subjective influence and human interference: Mathematics has great utilitarian worth here, but is untainted by the messiness of politics and human vulnerability. 'Failure', in these terms, is therefore constructed, ironically, as a condition of being an unknowing mathematical subject, of refusing to participate in the theatre of democracy. As we noted above, we want to problematise this rhetoric, and consider whether the refusal to participate in this way might be a more radically democratic act than acquiescence. We do not mean, however, to celebrate mathematical ignorance, but instead to refuse the presumption of ignorance on the part of so many potential 'citizens' that accompanies this common rhetoric.

In this common rhetoric, a citizen's purpose and worth is defined by their access to mathematical numeracy: 'Numeracy ... [is] ... required by all persons to function successfully within our technological world' (Ministry of Education, Province of British Columbia, 2007, p. 11) so that someone without access is a problem to the state and a 'failed' citizen. Our position using Rancière's perspective refuses this construction, and the implications of such a construction. In the common rhetoric, undemocratic forms that produce inequity, often in the name of 'necessity' or 'common sense' underwritten by modernisation discourses, work against mathematics education as a force of democratisation. For example, access to mathematics in institutions and programmes must of necessity be differentiated to satisfy the socioeconomic and political requirements of the nation state. Not all citizens are enabled to meet criteria of minimal mastery or to excel at mathematics. It is not for nothing that mathematics is most often the most divisive subject on the school curriculum (Dowling, 1998). Standardised testing, streaming or tracking systems in schools for mathematics and pronounced differentiated teaching practices in this subject, as well as other gatekeeping controls, ensure that a differentiated hierarchy of access is produced that emulates, assists, (re)produces, and is (re)produced by the hierarchy within capitalist relations of production. The high status of mathematics in the 'social division of labour of discourses' within schools and society, makes it a high-stakes game to play, and its 'strong grammar' (Bernstein, 2000) provides it with significant cultural value for those with the luck and privilege to have access to it as knowing subjects and citizens. Thus we reject the notion of 'successful citizenship' constructed accordingly along the lines of privileged access to mathematical culture and referenced in terms of 'innate capacities' and 'ability'; this discourse ensures that the privileged access is hidden, normalised, and often even justified under the auspices of being 'democratic' (Swanson, 2007a). 


\section{Moses and Gus reprise}

'Glocal' refusal as mathematics education takes shape is a positive rather than a negative enunciation: the stance of radical equality enables in action rather than constrains. It should not be surprising that so much school mathematics in most contexts is met with forms of resistance. The psychoanalytic notion that such resistance might be a positive sign of imminent intrapersonal insight aside (Appelbaum, 2008), it might be time for mathematics education to recognise refusal as a pervasive emotional experience that could be understood in generative terms instead of the usual and elaborate production of research and professional recommendations for erasing, co-opting, or circumnavigating resistance as a problem to be solved. Imagine a meeting of Moses and Gus, two people with very different backgrounds, motivations, dreams and fears; they agreed to join us in a new social enterprise: a mathematics education project as a people's theatre of democracy. This 'development' programme has at its heart the axiom of radical equality, and the notion that mathematics can bring people together as well as provide personal satisfaction; mathematics will be the central resource for strong and equitable communities characterised by creativity, joy, can-do attitudes, and the courage to act on their convictions (Appelbaum, 2011, 2012).

We turn for inspiration to the rise of People's Mathematics in the 1980s in South Africa (Adler, 1988; Bopape, 1998; Swanson, 2005). Although it never really gained traction, and it could be considered a very narrow, functionalist, arithmetical and impoverished form of mathematical content, in that moment there was a realisation that school mathematics in its presumptuousness of neutrality and superiority was at the same time colonising, and could be associated directly with the apartheid state and its intentions. In that moment of refusal, of disobedience to the norms of schooling in mathematics, mathematics became culpable of inequality. The emphasis on collectives in and out of school generated new conceptions of overlapping communities of mathematics education that would mutually buttress each other's efforts. And the mandate to create new curriculum materials that were informed by a critique of apartheid assumptions laid a strong foundation for dreams of a new democracy. Today, in the new South Africa, globalising neo-liberalism has pacified resistance, and the refusal of the People's Mathematics Movement is left to lie as a memory for instigation another day.

\section{Acknowledgement Competing interests}

We declare that we have no financial or personal relationship(s) which might have inappropriately influenced our writing of this article.

\section{Authors' contributions}

D.S. (Nelson Mandela Metropolitan University) and P.A. (Arcadia University) collaborated on the writing of this manuscript via email, taking turns adding to, editing and improving on the manuscript. The work draws on each author's previous research to reconsider and investigate a number of ethical, egalitarian and philosophical issues pertaining to democracy, education and development, whilst considering neo-liberal globalisation and citizenship as imbricated in such considerations.

\section{References}

Adler, J. (1988). Towards democratic mathematics education in South Africa. Lengwitch, March, 83-98.

Appelbaum, P. (1995). Popular culture, educational discourse and mathematics. New York, NY: State University of New York Press.

Appelbaum, P. (2008). Embracing mathematics: On becoming a teacher and changing with mathematics. New York, NY: Routledge.

Appelbaum, P. (2011, July). How to live a math circle. Paper presented at the Conference of the International Commission for the Study and Improvement of Mathematics Education, Barcelona, Spain.

Appelbaum, P. (2012). Mathematical practice as sculpture of utopia: Models, ignorance, and the emancipated spectator. For the Leaning of Mathematics, 32(2), 13-18.

Bernstein, B. (2000). Pedagogy, symbolic control and identity: Theory, research and critique. New York, NY: Rowman \& Littlefield.

Bopape, M. (1998). The South African new mathematics curriculum: People's mathematics for people's power? In P. Gates, \& T. Cotton (Eds.), Proceedings of the First Mathematics Education and Society Conference. Nottingham: The Centre for the Study of Mathematics Education, Nottingham University. Available from

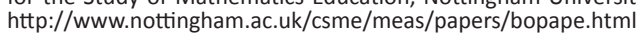

Dowling, P. (1998). The sociology of mathematics education: Mathematical myths/ pedagogic Texts. London: Falmer.

Hallward, P. (2009). Staging equality: Rancière's theatrocracy and the limits of anarchic equality. In G. Rockhill, \& P. Watts (Eds.), Jacques Rancière: History, politics, aesthetics (pp. 140-157). Durham, NC: Duke University Press.

Lawler, B. (2010). Fabrication of knowledge: A framework for mathematical education for social justice. In U. Gellert, E. Jablonka, \& C. Morgan (Eds.), Proceedings of the Sixth International Mathematics Education and Society Conference (pp. 330-350) Freie Universität Berlin. Available from http://www.ewi-psy.fu-berlin.de/en/v/ mes6/documents/proceedings/Band_1_Finale.pdf

Magill, M. (2000). Vik Muniz. Bomb, 73. Available from http://bombsite.com/ issues/73/articles/2333

Ministry of Education, Province of British Columbia. (2007). Mathematics $K$ to 7 : Integrated Resource Package 2007. Available from http://www.bced.gov.bc.ca/ $\mathrm{irp} / \mathrm{pdfs} /$ mathematics/2007mathk7.pdf

Myers, T. (2003). Slavoj Zizek. New York, NY: Psychology Press.

Rancière, J. (2009). The method of equality: An answer to some questions. In G. Rockhill, \& P. Watts (Eds.), Jacques Rancière: History, politics, aesthetics (pp. 273-788). Durham, NC: Duke University Press.

Rancière, J. (2012). The people's theatre: A long drawn-out affair. In J. Rancière (Ed.), The intellectual and his people: Staging the people, Vol. 2 (pp. 1-40). (D. Fernbach, Trans.). London: Verso.

Skovsmose, O. (2012). Beyond post-modernity in mathematics education. The Mathematics Enthusiast, 9(3), 233-252. Available from http://www.math.umt. edu/tmme/vol9no3/Article1Skovsmose_pp233_252.pdf

Skovsmose, O., \& Valero, P. (2001). Breaking political neutrality: The critical engagement of mathematics education with democracy. In B. Atweh, H. Forgasz, $\&$ B. Nebres (Eds.), Sociocultural research on mathematics education: An international perspective (pp. 37-55). Mahwah, NJ: Erlbaum.

Swanson, D.M. (2005). Voices in the silence: Narratives of disadvantage, social context and school mathematics in post-apartheid South Africa. Unpublished doctoral dissertation. University of British Columbia, Vancouver, Canada. Available from https://circle.ubc.ca/handle/2429/17343

Swanson, D.M. (2007a). A life for Aprile: Social justice as a search of/for the soul. In K. Nolan, \& E. de Freitas (Eds.), Opening the research text: Critical insights and in(ter) ventions into mathematics education (pp. 231-239). New York, NY: Springer Press.

Swanson, D.M. (2007b). Cultural beads and mathematical AIDS: A critical narrative of disadvantage, social context and school mathematics in post-apartheid South Africa, with reflections and implications for glocal contexts. Philosophy of Education Journal, 21(2), 1-78. Available from http://www.people.ex.ac.uk/ of Education Journal, 21(2),

Swanson, D.M. (2010). Paradox and politics of disadvantage: Narratizing critical moments of discourse and mathematics pedagogy within the "glocal". In M. Walshaw (Ed.), Unpacking pedagogy: New perspectives for mathematics (pp Walshaw (Ed.), Unpacking pedagogy: New perspectives
245-263). Greenwich, CT: Information Age Publishing.

Swanson, D.M. (2012). The owl spreads its wings: Global and international education within the local from critical perspectives. In Y. Hébert, \& A.A. Abdi (Eds.) Critical perspectives on international education (pp. 333-347). Rotterdam: Sense Publishers. 